\title{
Review Paper: Mesenchymal Stem Cells: Signaling Pathways in Transdifferentiation Into Retinal Progenitor Cells
}

\author{
Hamid Aboutaleb Kadkhodaeian ${ }^{1^{*}}$ (i)
}

1. Nervous System Stem Cell Research Center, Semnan University of Medical Sciences, Semnan, Iran.

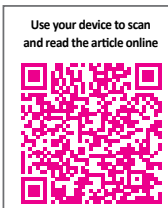

Citat on: Aboutaleb Kadkhodaeian, H. (2021). Mesenchymal Stem Cells: Signaling Pathways in Transdifferentiation Into Retinal Progenitor Cells. Basic and Clinical Neuroscience, 12(1), 29-42. http://dx.doi.org/10.32598/bcn.9.10.510

dol http://dx.doi.org/10.32598/ben.9.10.510

\section{(c) (1) (\$)}

Article info:

Received: 16 Jul 2018

First Revision: 25 Aug 2018

Accepted: 2 Feb 2020

Available Online: 01 Jan 2021

Keywords:

Signaling pathways,

Transdifferentiation,

Mesenchymal stem cells,

Retinal cells

\section{A B S T RA C T}

Several signaling pathways and transcription factors control the cell fate in its in vitro development and differentiation. The orchestrated use of these factors results in cell specification. In coculture methods, many of these factors secrete from host cells but control the process. Today, transcription factors required for retinal progenitor cells are well known, but the generation of these cells from mesenchymal stem cells is an ideal goal. The purpose of the paper is to review novel methods for retinal progenitor cell production and selecting a set of signaling molecules in the presence of adult retinal pigment epithelium and extraocular mesenchyme acting as inducers of retinal cell differentiation. 


\section{Highlights}

- Extracellular signaling pathways are involved in the generation of retinal progenitor cells.

- A comparison was made between signaling pathways in the transdifferentiation of mesenchymal, neural, and retinal stem cells.

- Mesenchymal stem cells are essential in the generation of retinal progenitor cells.

\section{Plain Language Summary}

Cell replacement therapy is a promising way to treat many diseases. Scientists are interested in finding safe cells with sufficient potential and selecting efficient methods for generating specific cells without tumorigenicity and ethical considerations. Molecular realization of cellular differentiation is the primary key to the production of the cell with particular potentials. The retina is the most critical layer in communicating with the outside environment. Many retinal diseases are associated with cellular disorders. Therefore, cell therapy is a new window in treating these diseases. However, according to the retinal environment, selecting the right cell and cell differentiation method is vital for cell transplantation. Discovering the mechanism of trans-differentiation and signaling pathways in integrated cells in the retina is very important for clinical trials. Therefore, the exact definition of the courses and molecules involved in retinal cell therapy is essential.

\section{Introduction}

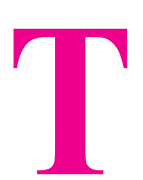

here are several different factors for controlling ocular tissues in the optic vesicle stage, such as extracellular factors and intrinsic signals (Fuhrmann, 2010). The distal/ventral part of the optic vesicle develops the neural retina, while the Retinal Pigment Epithelium (RPE) emerges from the dorsal region (Hirashima, Kobayashi, Uchikawa, Kondoh, \& Araki, 2008; Kagiyama et al., 2005). At the optic vesicle stage, the neuroepithelium is bipotential (Araki \& Okada, 1977; Clayton, Pomerai, \& Pritchard, 1977; Horsford et al., 2005; Itoh, Okada, Ide, \& Eguchi, 1975; Opas, Davies, Zhou, \& Dziak, 2004; Rowan, Chen, Young, Fisher, \& Cepko, 2004; Westenskow, McKean, Kubo, Nakagawa, \& Fuhrmann, 2010). The first genes that show specific expression in the retina and RPE are the homeobox gene Vsx2, the bHLH (basic helix-loop-helix) transcription factor, and microphthalmia transcription factor (Mitf) (Burmeister et al., 1996; Green, Stubbs, \& Levine, 2003; Hodgkinson et al., 1993; Nguyen \& Arnheiter, 2000). Extraocular mesenchyme is required to express RPE-specific genes such as Mitf, its target melanosomal matrix protein MMP115, and Wnt13, in chick optic vesicles cultures. In the mouse, when Mitf is expressed, extraocular mesenchyme surrounds the budding optic vesicle at its early stages (Fuhrmann, 2010). Ocular and extraocular tissues express Fibroblast Growth Factor (FGF) li- gands and their receptors (De Iongh \& McAvoy, 1993; Pittack, Grunwald, \& Reh, 1997; Vogel-Höpker et al., 2000). The studies showed that FGF results in transdifferentiation of RPE into retinal cell types (Galy, Neron, Planque, Saule, \& Eychene, 2002; Guillemot \& Cepko, 1992; Hyer, Mima, \& Mikawa, 1998; Mochii, Mazaki, Mizuno, Hayashi, \& Eguchi, 1998; Park \& Hollenberg, 1989; Pittack et al., 1997). The extraocular mesenchyme is a mixture of different growth factors, which act as an inducer of differentiation of neural embryonic stem cells towards their fate (Fuhrmann, 2010; Fuhrmann, Levine, \& Reh, 2000; Messina, Casarosa, \& Murenu, 2011).

Neural System Stem Cells (NSCs) are derived from different sources such as the embryonic, fetal, and adult nervous systems. The functions of NSCs are to produce other cells and differentiate them into progenitor cells (Weiner, 2008). Neural stem cells have multipotentiality for differentiation. In vitro, under the conditioned medium, these cells become floating cell aggregates, known as neurospheres, and in the form of adherent cell monolayer called neural stem cells (Matthew, 2011). There is little information about the fundamental mechanisms regulating cell fate in adult NSCs than developing neural stem cells. Transplantation of NSCs into the adult CNS results in differentiation into proper cell types after an initial culture period, which we know as neurospheres (Zigova, Sanberg, \& Sanchez-Ramos, 2002). The embryonic cortical and spinal cords NSCs are similar in self-renewal properties and multipotency (Kelly, 
Karsten, Geschwind, \& Kornblum, 2009). NSCs differentiate into neural lineage cells both in vitro and in vivo (Bae et al., 2011; Choi et al., 2005; Fujimura, Ogawa, Mizuno, Fukunaga, \& Suzuki, 2005; Kelly et al., 2009; Krabbe, Zimmer, \& Meyer, 2005; Montzka et al., 2009; $\mathrm{Xu}$ et al., 2008). These cells show multipotentiality like embryonic cortical stem cells (Redi, 2011).

1.1. Mesenchymal stem cells, importance in the generation of retinal progenitor cell

Different studies used stem cells to treat degenerative eye diseases (Table 1) (Scheven, 2015; Wong, Poon, Pang, Lian, \& Wong, 2011). In these studies, mesenchymal stem cells or, in specific terms, Bone Marrow Stromal Stem Cells (BMSCs) are the study targets. BMSCs are versatile, i.e. have plasticity (Redi, 2011), neuroprotection, and immune modulation properties. They introduce no ethical problem and be used in an autologous fashion (Barry \& Murphy, 2004; Caplan, 1991; Catacchio et al., 2013; Chotima, 2007; Duan, Xu, Zeng, Wang, \& Yin, 2013; Levkovitch-Verbin et al., 2010).

Studies showed that many subpopulations of Mesenchymal Stem Cells (MSCs) could express OCT4, Nanog, and Rex1 at the mRNA and protein levels (Wong et al., 2011). BMSCs are a suitable cell source for the treatment of eye diseases. BMSCs have an essential role in tissue repair.

These cells migrate into the injured site and integrate with host tissue (Catacchio et al., 2013; Chotima, 2007; Duan et al., 2013). These cells can differentiate into RPE (Catacchio et al., 2013; Hatzistergos et al., 2010; Stern \& Temple, 2011) and retinal cells (Chotima, 2007; Wong et al., 2011; Xu \& Xu, 2011). These cells have been studied in the clinical trials of eye diseases such as Age-Related Macular Degeneration (ARMD), glaucoma, diabetic retinopathy, retinitis pigmentosa, ischemic retinopathy, macular dystrophy, and optic atrophy (Mead et al., 2015; Wong et al., 2011). Thus, a variety of protocols have been used for the generation of RPE and retinal cells (Bharti et al., 2012; Bharti, Miller, \& Arnheiter, 2011; Bharti, Nguyen, Skuntz, Bertuzzi, \& Arnheiter, 2006; Cho et al., 2012; Fuhrmann, 2010; Fujimura, Taketo, Mori, Korinek, \& Kozmik, 2009; Lamba, Karl, Ware, \& Reh, 2006; Müller, Rohrer, \& Vogel-Höpker, 2007; Tang et al., 2010).

One method for producing cells in vitro is the coculture technique. To induce retina and RPE cell preparation, researchers carried out several experiments. This method and generated cells are morphologically like native cells and, after transplantation in animal model migrate and integrate into host tissue (Catacchio et al., 2013; Duan et al., 2013; Hatzistergos et al., 2010; Li et al., 2007; Messina et al., 2011; Stern \& Temple, 2011). But orienting retinal layers in the culture (outer extraocular, middle RPE, and inner retina) is a benefit to produce cells in each layer. 3D coculture is a new tool for developing organoids to model tissues (Huch \& Koo, 2015). Therefore, the combination of extracellular matrix and 3D culture systems with the knowledge of the signaling pathways is vital for tissue repair. The studies showed that several organoids derived from adult stem cells (Huch \& Koo, 2015).

Then, Extraocular Mesenchyme (EOM) and RPE cells together may induce differentiation of the neural stem cells into retinal cells and RPE cells more potently. This procedure is a new method for the production of retinal/ RPE cells in vitro.

1.2. Evolutionary molecules and signaling pathways in mesenchymal, neural, and retinal stem cells

In comparison between Neural Stem Cells (NSCs), Retinal Stem Cells (RSCs) in the eye field stage, early Retinal Progenitor Cells (RPCs), and late Retinal Progenitor Cells (RPCs) in transcription factors expression level (Table 1) from all markers that neural stem cells express, the more attention in retinal differentiation is to Pax6,

Table 1. Genes expressed in different stem cells

\begin{tabular}{ccccc}
\hline Stem Cells Markers & Retinal Stem Cells (RSCs) & Neural Stem Cells (NSCs) & $\begin{array}{c}\text { Early Retinal Progenitor } \\
\text { Cells }\end{array}$ & $\begin{array}{c}\text { Late Retinal Progenitor } \\
\text { Cells }\end{array}$ \\
\hline Pax6 & $\mathrm{V}$ & $\mathrm{V}$ & $\mathrm{V}$ \\
Otx2 & $\mathrm{V}$ & $\mathrm{V}$ & $\mathrm{V}$ \\
Notch1 & & $\mathrm{V}$ & $\mathrm{V}$ \\
Sox2 & $\mathrm{V}$ & $\mathrm{V}$ \\
Lhx2 & $\mathrm{V}$ & & $\mathrm{V}$ \\
\hline
\end{tabular}




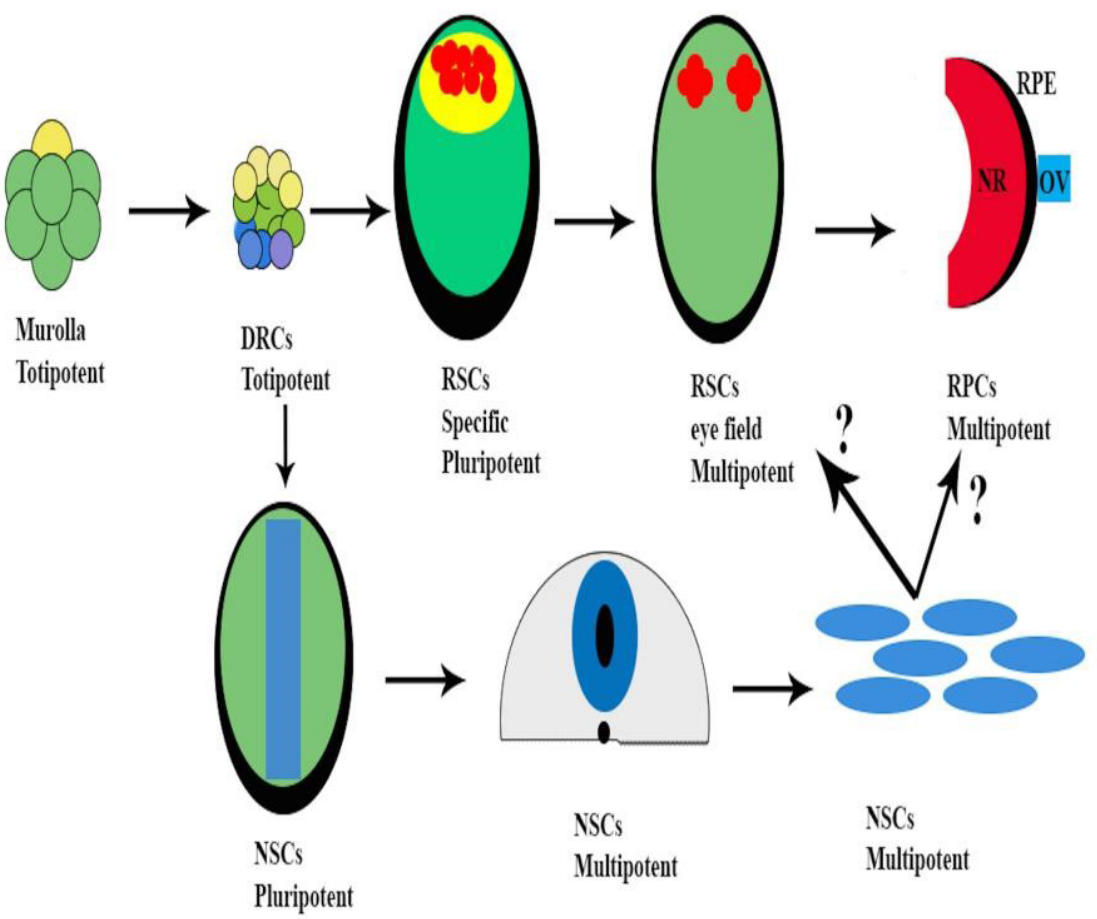

Figure 1. Schematic representation of similarity in the potency of stem cells for the generation of retinal cells

Blastomeres in the animal pole of the embryo can differentiate into the eye, and other blastomeres could differentiate into neuroectoderm cells. Cells in RPCs and NSCs are similar in potency and differentiation and may generate RPCs or different retinal cell types.

DRCs: Dorsal retinal cells; RSCs: Retinal stem cells; NSCs: Neural stem cells; RPCs: Retinal progenitor cells; RPE: Retinal pigment epithelium; NR: Neural retina; OV: Optic vesicle.

Sox2, Otx2, and Notch1 transcription factors (Faigle \& Song, 2013; Kuhn \& Eisch, 2014; Temple, 2001).

Pax6 and Otx2 are two important factors for RSCs while, Pax6, Sox2, and Notch1 are for early and late Retinal Progenitor Cells (RPCs) (Cwinn et al., 2011; Fuhrmann, 2010; Hennig, Peng, \& Chen, 2008; Peng, Ahmad, Ahmad, Liu, \& Chen, 2005; Swaroop, Kim, \& Forrest, 2010). Later 4 stem cells are like each other in the expression of transcription factors Pax6 and NSCs and RSCs in Otx2. NSCs and early and late RPCs in Notch1 and NSCs and early RPCs in Sox 2 are similar. The studies showed that maintaining neurogenic competence and multipotency in RPCs depends on the balance between Sox2 and Pax6 (Brzezinski \& Reh, 2015; Xiang, 2013).

As eye development has become clear (Fuhrmann, 2010; Sernagor, Eglen, Harris, \& Wong, 2012; Zaghloul, Yan, \& Moody, 2005), a subtype of totipotent morula cells competent to totipotent dorsal retinal stem cells and RSCs derived from DRCs under the influence of Eye Field Transcription Factors (EFTFs) dedicated and formed optic vesicle and optic cup. These cells are plu- ripotent and, in the next stage, differentiate into RPCs. The last cells are multipotent and included early and late retinal progenitor cells, Retinal Pigment Epithelium (RPE), and optic stalk (Figure 1).

Other blastomeres in equatorial and ventral animal poles could reprogram in response to interaction with their neighbor's cells and generate normal retinal cells (Sernagor et al., 2012; Zaghloul et al., 2005). Therefore, animal pole blastomeres have different potential to generate retina. At the end of gastrulation, these cells become neuroectoderm and neural stem cells with multiple competencies (Kuhn \& Eisch, 2014). Signaling pathways in the embryonic stage for neural induction are BMP antagonists, FGF/ERK, and Wnt (Turner et al., 2014). Multipotent Bone Marrow Stromal Stem Cells (BMSCs) are in the mesenchymal lineage (Barry \& Murphy, 2004; Carido et al., 2014; Machalińska et al., 2009; Redi, 2011) and have the potential to differentiate into NSCs (Catacchio et al., 2013; Deng, Obrocka, Fischer, \& Prockop, 2001; Egusa, Schweizer, Wang, Matsuka, \& Nishimura, 2005; Hatzistergos et al., 2010; Jiang et al., 2010; Ramrattan et al., 1994; Woodbury, Reynolds, \& Black, 2002). 
Table 2. Signaling pathways used by stem cells in differentiation processes

\begin{tabular}{|c|c|c|c|c|c|}
\hline $\begin{array}{l}\text { Signaling Path- } \\
\text { ways }\end{array}$ & $\begin{array}{c}\text { Retinal Stem Cells } \\
\text { (RSCs) }\end{array}$ & $\begin{array}{c}\text { Neural Stem Cells } \\
\text { (NSCs) }\end{array}$ & $\begin{array}{l}\text { Early Retinal Pro- } \\
\text { genitor Cells }\end{array}$ & $\begin{array}{l}\text { Late Retinal Pro- } \\
\text { genitor Cells }\end{array}$ & $\begin{array}{c}\text { Mesenchymal } \\
\text { Stem Cells (MSCs) }\end{array}$ \\
\hline Shh & $v$ & $v$ & $v$ & $v$ & \\
\hline BMP & $v$ & $v$ & $v$ & & $v$ \\
\hline FGF & & $v$ & $v$ & & $v$ \\
\hline Notch1 & & $v$ & & $v$ & \\
\hline Wnt & v & v & & & v \\
\hline
\end{tabular}

NEUR SCIENCE

As mentioned above, NSCs are in neural lineage like BMSCs multipotent (Table 1) (Bae et al., 2011; Choi et al., 2005; Fujimura et al., 2005; Kelly et al., 2009; Krabbe et al., 2005; Montzka et al., 2009; Xu et al., 2008). The question is whether NSCs could generate retinal cells. As for the expression of markers explained later, NSCs may be similar to RSCs at the eye field stage and could create cells of the optic vesicle and optic cup. Studies showed that mouse Embryonic Stem Cells (mESCs) in culture medium containing N2, b27, serum, and Retinoic Acid (RA), result in the generation of a neural precursor that express Sox 2 and Sox1. These cells in low levels of Nodal and Activin gained neural fate (Fujimura et al., 2009).

In vivo studies showed that transplantation of NSCs in the injured retina could migrate and integrate and differentiate into retinal cells such as photoreceptors cells but not retinal ganglion cells (Mead et al., 2015). In other words, NSCs may be differentiated to RPCs and produce neural retina, RPE, and optic stalk. These similarities arise from declaration and homogeny in transcription factors released from NSCs (Faigle \& Song, 2013; Kuhn \& Eisch, 2014; Mead et al., 2015; Temple, 2001) in contrast to RSCs and RPCs. Therefore, NSCs could generate early and late PRCs in vitro. To clarify this potentiality, we could trace signaling pathways that these cells use (Table 2).

From pathways that RSCs use for differentiation (Sinn \& Wittbrodt, 2013; Wang, 2017), two pathways, Shh, and BMP are essential. Shh, BMP, FGF, EGF, Notch1, and Wnt are pathways in NSCs (Faigle \& Song, 2013).

Interestingly, BMSCs also use BMP, FGF, and Wnt signaling pathways. Two other stem cells, early and late retinal stem cells like the above cells, use BMP, FGF, EGF, and Notch1 signaling pathways.
According to Table 2, there is a similarity in signaling pathways in NSCs with other stem cells. Due to the similarity in differentiation potential, BMSCs, NSCs, RSCs, and RPCs are similar and could act in the same manner. Shh is a common pathway between NSCs, RSCs, early and late RPCs, and BMP is a common factor to BMSCs, NSCs, RSCs, and early RPCs. Also, FGF is common between BMSCs, NSCs, and early RPCs, and Finally, Wnt is common between BMSCs, NSCs, and RSCs. Therefore, theoretically, BMSCs and NSCs may be differentiated into retinal cells (Dong, Pulido, Qu, \& Sugaya, 2003; Yuan et al., 2003). Although NSCs could differentiate into RPCs, early and late RPCs and BMSCs could differentiate into RSCs and late RPCs (Moviglia, Blasetti, Zarate, \& Pelayes, 2012; Sevlever, Miriuka, \& Pitossi, 2015). The studies have shown that Wnt (Nakamura, de Paiva Alves, Veenstra, \& Hoppler, 2016) and BMP (Pandit, Jidigam, Patthey, \& Gunhaga, 2015; Singh \& MacLaren, 2011; Wong, Trembley, Wahab, \& Viczian, 2015) identify the linage and fate of the retina (Sernagor et al., 2012; Xiang, 2013) and Wnt, FGF (Sernagor et al., 2012), BMP, Nodal and Retinoic Acid (RA) (Brzezinski \& Reh, 2015; Zhou et al., 2015) are determined by neural pattern (Turner et al., 2014).

In the cascade view, Wnts and BMPs signaling pathways are essential in the specification of eye field (Nakamura et al., 2016; Wang, 2017), and following FGF signaling pathway and EFTFs cause the expression of PERK that results in activation and expression of Sox 2 and Vsx2. The expression of these two factors results in the inhibition of MITF. Besides, Notch pathway activation causes activation of Pax6 (Fuhrmann, 2010; Wang, 2017).

Therefore, Pax6 as a regulator of eye formation, followed by activation of the FGF signaling pathway, results in the formation of RPCs. Then, it seems that signaling pathways such as Wnt, BMP, FGF, Nodal, and RA and followed by Wnt, FGF and in the final step FGF, 


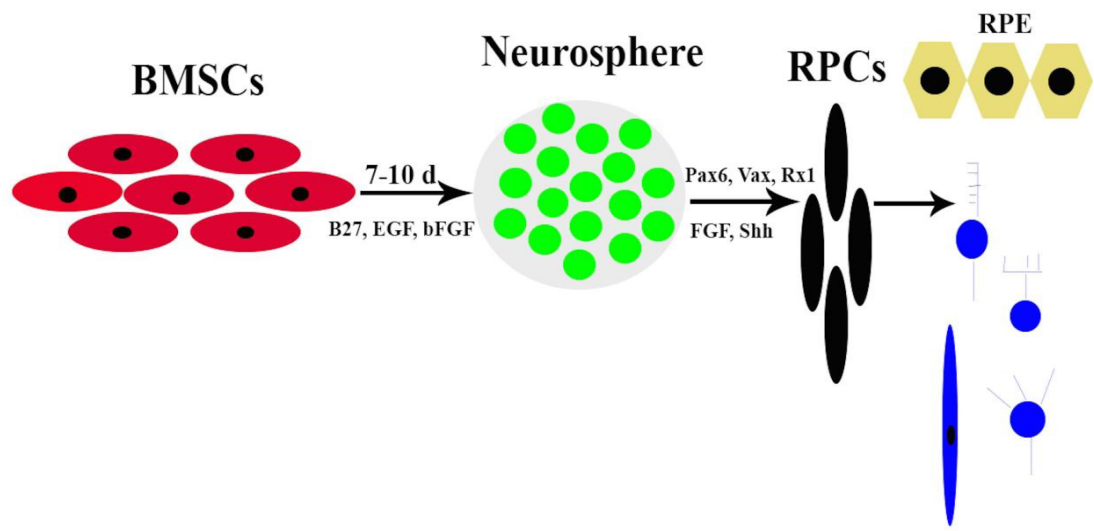

Retinal cells

Figure 2. Schematic illustration of possible mechanism in our hypothesis for the differentiation of BMSCs into RPE/retinal cells

Bone marrow stromal stem cells under the influence of signaling factors cause aggregation called neurosphere. These cells, under the influence of eye signaling and transcription factors for the retina, differentiate into retinal progenitor cells and finally into RPE and different retinal cells.

BMSCs: Bone marrow stromal stem cells; RPCs: Retinal progenitor cells; RPE: Retinal pigment epithelium.

Shh, and transcription factors (Adler \& Canto-Soler, 2007; Faigle \& Song, 2013; Sinn \& Wittbrodt, 2013; Zaghloul et al., 2005) result in the generation of RPCs. If a similar cascade induces NSCs, given that NSCs are similar to RSCs in multipotency and could use identical signaling pathways, it can differentiate into RPCs and early and late RPCs in vitro (Dong et al., 2003; MacLaren \& Pearson, 2007).

The studies showed that BMSCs under the influence of differentiation medium containing B27, EGF, and bFGF could change their fate and transdifferentiate into aggregated floating cells called neurosphere (Figure 2). After plating these cells, generated neural stem cells could express specific markers for neural and glial cells (Aruta et al., 2011; Bae et al., 2011; Choi et al., 2005; Fujimura et al., 2005; Kelly et al., 2009; Krabbe et al., 2005; Montzka et al., 2009; Stern \& Temple, 2011; Xu et al., 2008). These cells may have the potential to differentiate into RPCs and finally RPE or retinal cells.

1.3. Factors and signaling molecules secreted from EOM and adult RPE

Extraocular mesenchyme cells surrounding the optic vesicle and optic cup secrete different factors and molecules. The diencephalon and mesencephalon of prosencephalon are two primary sources of extraocular mesenchymal cells (Fuhrmann, 2010; Kagiyama et al., 2005). EOM cells secrete several factors that affect adjusting optic cup cells (RPE cells and neural retina) and change their fate and function (Adler \& Canto-Soler, 2007; Fuhrmann, 2010; Messina et al., 2011; Yang, 2004). The healthy and functionality of the neural retina and choroid layer depends on RPE monolayer (Kadkhodaeian et al., 2018; Dutt, Douglas, \& Cao, 2010; Elner et al., 2003; Hogan, Alvarado, \& Weddell, 1971; Korte, Reppucci, \& Henkind, 1984; Young \& Bok, 1970; Zarbin, 2004). RPE released factors directly change the fate of neural retinal cells (Dutt et al., 2010). In other words, the correlation between EOM, RPE cells, and neural retina leads to the development of eyecup.

In Table 3, secreted factors by EOM and RPE cells are listed. They are common in three factors, TGF-B, FGF, and BMP. It seems that the influence of these factors increases by using these two cells together and could activate signaling pathways such as BMP, FGF, and TGF-B

BMP signaling cascade is necessary for retinal specification and preservation of retinal domain (Adler \& Canto-Soler, 2007; Faigle \& Song, 2013; Fuhrmann, 2010; Yang, 2004). Inhibition of BMPs and Wnts signaling cause neuroectodermal specification (Sernagor et al., 2012; Sinn \& Wittbrodt, 2013), retinogenic fate (Sernagor et al., 2012; Sinn \& Wittbrodt, 2013), and retinal formation (Turner et al., 2014; Wong et al., 2015).

In Xenopus, noggin upregulates EFTSs and causes retinal progenitor cell fate. In other words, noggin inhibits the BMP4 and result in retinal formation. The suggested mechanism for neural induction is inhibition of 
Table 3. Extraocular and adult Retinal Pigment Epithelium (RPE) cells factors and signaling molecules

\begin{tabular}{|c|c|c|}
\hline Signaling Molecules & Extraocular Mesenchyme & Adult RPE \\
\hline TGF- $\beta$ & v & v \\
\hline FGFs & $v$ & v \\
\hline BMP & $\checkmark$ & $v$ \\
\hline CNTFs & & v \\
\hline BDNFs & & $v$ \\
\hline NGFs & & $v$ \\
\hline bFGFs & & v \\
\hline
\end{tabular}

BMP-Smad1 and Activin/TGFB-Smad2. Smad1/5/8 and Smad2/3 are downstream of BMP and Activin pathways. Activation of noggin causes the expression of Otx2, Rax, Pax6, Six3, and Lhx2 (Wong et al., 2015). Noggin overexpression in ventral blastomeres causes retina formation. Inhibition of BMPs and Activin in human embryonic stem cells (hESCs) result in neural induction (Wong et al., 2015). Studies showed that antagonist Wnt and BMP/ Activin and IGF on the hESCs result in the generation of retinal progenitor (Wong et al., 2015).

The studies showed that BMP and Wnt are necessary for RPE generation in chick, and BMP is essential to maintain Rax2+ and neural retinal differentiation in the optic vesicle. Still, it is not needed for Mitf+ RPE induction in optic vesicle explant (Pandit et al., 2015). FGF is essential for retinal patterning, but TGF-B is an inhibitory molecule. BMP signaling is vital in retinal pattern formation as in D-V axial patterning in the nervous system, in $\mathrm{D}-\mathrm{V}$ axial determination of the optic cup and neural retina, establishing the topographic projection map of the RGC axons in their target fields. Also, several studies implicated BMP involvement in retinal cell survival (Adler \& Canto-Soler, 2007; Yang, 2004).

In chick, at neural tube/optic vesicle stage, BMP signaling causes maintenance of eye field and specification of neural retinal cells. In mice, the BMP pathway is necessary for retinal growth and early retinal neurogenesis (Pandit et al., 2015). Activin, one of the TGF-B family members, secreted from EOM cause RPE development (Adler \& Canto-Soler, 2007; Messina et al., 2011). In other words, Activin triggers Mitf, Wnt13, MMP115 and inhibits the Pax6, Chx10, and Optx2 (Messina et al., 2011).
RPE cells are post-mitotic cells that have one incomplete cell division (Hogan et al., 1971). Therefore, they are seen as binuclear in vivo (Dutt et al., 2010). In vitro, under the influence of different factors and microenvironment, they transdifferentiate into other cells like retinal cells (Wong et al., 2011). In other words, in a medium containing bFGF, BDNF, CNTF, and alpha TGF, RPE cells transdifferentiate into retinal cells, especially photoreceptors (Dutt et al., 2010).

Signaling molecules such as bFGF, CNTF, FGF, and Hh (Yang, 2004) secrete from adult RPE cells in vitro (Dutt et al., 2010). Then, regulatory systems in these cells are responsible for changing the fate and morphology in vitro. Uses of adult RPE cells have two advantages, 1secreted growth factors induce differentiation pathways in NSCs (Dutt et al., 2010) and 2- transdifferentiation of adult RPE cells may influence later NSCs differentiation into retinal cells. Studies showed that cells derived from the RPE layer, plated at clonal density, could form a neural sphere if treated with FGF2 or EGF (Yang, 2004).

As mentioned, signaling molecules such as Shh, TGFb/ BMP, FGF, and Wnt have an essential role in optic cup development and RPCs generation (Zaghloul et al., 2005). The Shh has a different role in retinogenesis and making developmental decisions. This factor separates optic primordia through repressing expression of an eye field specification, optic cup regionalization by the expression of Pax6, Pax2, Vax, Rx1, Mitf, and Otx2, and the formation of differently-biased RPCs thought several cytokines, including FGF and transcription factors (Dutt et al., 2010; Zaghloul et al., 2005).

The sonic hedgehog signaling pathway is required for maintenance of RPE fate in the ventral optic cup 


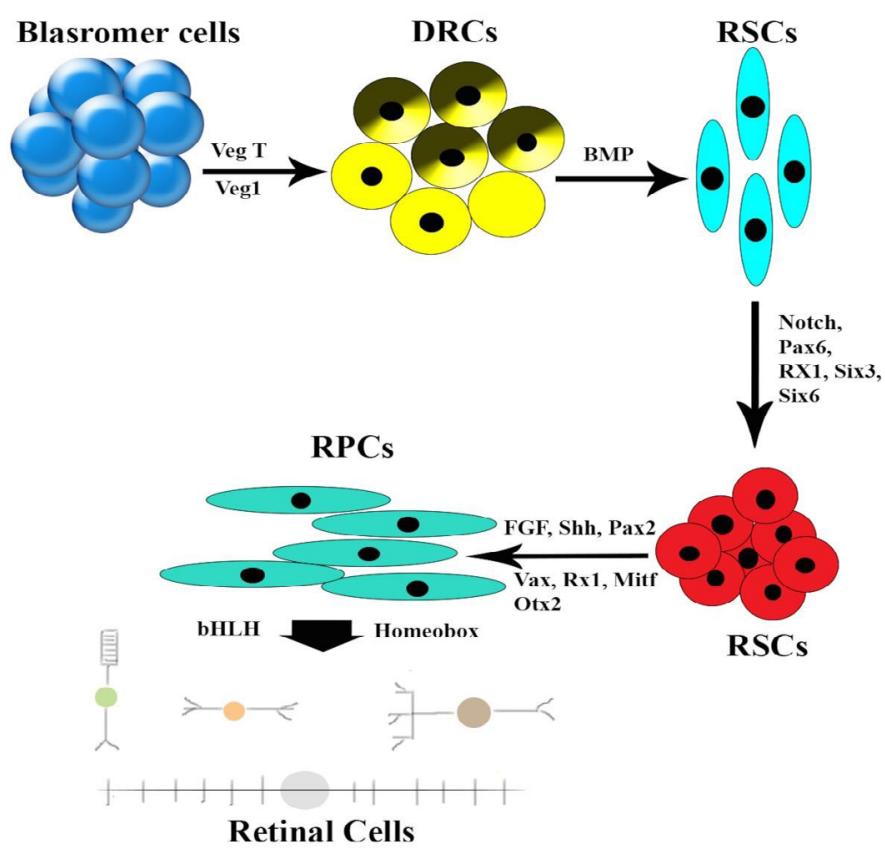

NEUR SCIENCE

Figure 3. Generation of retinal cells from blastomeres under the influence of different signaling molecules and factors

In blastomeres, localized VegT and Vg1 are involved in the initial step in retinogenesis. BMP signaling gradient causes selection of DRCs and under the influence of

EphrinB1 and FGF cells move into the eye field. Also, Notch signaling via expression of Pax6, Pax2, Vax, Rx1, Mitf, Six6 causes specification of eye field RSCs. FGF and Shh signaling pathways through the expression of EFTFs result in optic cup regionalization and generation of RPCs. The combination of homeobox and bHLH transcription factors causes differentiation of RPCs into retinal cells.

DRCs: Dorsal retinal cells; RSCs: Retinal stem cells; RPCs: Retinal progenitor cells.

and reduced Shh signaling increased proliferation of RPE and transdifferentiation into the retina (Fuhrmann, 2010). It is suggested that the Shh factor by attaching to intramembranous protein like patched, my be activated slowly. The activation of Gli causes an effect on specific transcription factors, for example, Pax6 and Rx1. Transcription factors of Pax6, Rx, LHx2, and Chx10 guide the optic vesicle toward the neural retina (Dutt et al., 2010; Wang, 2017).

Besides, Shh affects primitive RPE tissue and inhibits Pax6, Mitf, and Otx2 (Wang, 2017). In other words, in response to graded Shh, Pax2 and Vax genes are expressed in the region adjacent to the midline and generate the optic stalk and ventral retinal fate, since Pax6 and $\mathrm{Rx}$ are expressed in site further distal to the midline and defines the optic cup. Also, Shh signal levels play a role in regulating the expression of the RPE determinants, i.e. Otx2 and Mitf (Dutt et al., 2010; Wang, 2017).

These factors may direct the optic vesicle to RPE. Therefore, the use of Shh along with Pax6 and Rx induc- es cells into the neural retina and RPCs. Besides, these molecules inhibit factors related to the RPE layer and optic stalk. For example, Pax6 has an inhibitory role in Pax 2 and Chx10 on Mitf (Wang, 2017). Studies showed that Shh regulates the Ciliary Margin Zone (CMZ) in fish, amphibians, and chicken. CMZ is absent in mice but increases the activity of Shh signaling in mouse causing the proliferation of progenitors (Wang, 2017).

\subsection{Extracellular signaling systems in generation} of RPCs

As mentioned before, Fibroblast Growth Factor (FGF) has a vital role in retinal development. FGF signal causes neural retina specification and organizes the double-layered optic cup (Adler \& Canto-Soler, 2007; Dutt et al., 2010). In general, FGF roles during eye development include forebrain development, eye field specification, RPCs differentiation (Figure 3), eye field split, optic vesicle evagination, optic cup formation, and retinal differentiation (Sinn \& Wittbrodt, 2013). 
Shh and FGF signaling influence the cell-intrinsic decision of RPCs (Sernagor et al., 2012). Studies showed that neutralize the FGF2 blocks neural differentiation, and adding the FGF to the culture medium causes the presumptive RPE to differentiate into the retinal layer. FGF suppresses genes of RPE determination; therefore, intracellular determinants for RPE may be stopped by a high concentration of FGF (Dutt et al., 2010). Several types of FGF molecule exists in the different area of developing retina (Adler \& Canto-Soler, 2007; Messina et al., 2011) and have a distinct effect on the retina. Among these factors, FGF8 causes the conversion of RPE into the neural retina, and FGF2 has an inhibitory role on it (Adler \& Canto-Soler, 2007). Whereas FGF1 or FGF2 downregulates Mitf expression and interferes with the pigmentation of cultured mouse eyes (Dutt et al., 2010).

Secreted FGF from surface ectoderm have an induction role in neural retina formation and cause expression of FGF8 and FGF9. These two factors result in the boundary between the neural retina and RPE (Adler \& Canto-Soler, 2007; Messina et al., 2011). FGF9 is usually expressed by the distal optic vesicle in the mouse. Miss-expression of FGF9 by the alpha crystalline in the lens causes dorsal RPE to convert into the neural retina (Dutt et al., 2010). FGF2, 8, 3, FGFR1, and Spry2 are expressed in the central segment of the developing retina. FGF 8, 3 signalings are necessary for the initial neurogenic switch in the retina (Sernagor et al., 2012). FGF9, FGFR1, 2, CRF are seen in the boundary between the central and peripheral portion, and FGF1, 19, FGFR1, and FGFR1, 2 are expressed in the peripheral neural retina (Adler \& Canto-Soler, 2007).

Signaling molecule BMP is expressed in a different portion of optic vesicle as BMP4 and noggin in peripheral and noggin in the central part of the neural retina are seen (Adler \& Canto-Soler, 2007). Expression of noggin results in RPE transdifferentiation into neuroepitheliumlike tissue (Adler \& Canto-Soler, 2007). Also, Wnt5a, 7b, 11 and Fz2, 3,5,8 and Sfrp1, 2 are expressed in the central portion and Wnt5a, 7b, 2b, 2 and Fz2, 3,5,1,4,6,7 and Sfrp1, 2 in dorsal part and finally Wnt5a, 7b, and Fz2, 3,5 and Sfrp1, 2 between the previous parts.

Therefore, extracellular signaling molecules such as FGF, BMP, Wnt (non-canonical) affect the expression of transcription factors like Rx, Pax6, Six3, Lhx2, Six6/ Optx2, Et, tll, Hes1 and Otx2 (Messina et al., 2011) and cause the generation of RPCs. The studies show several genes like above, and ABCG2, CR3, FABP7/B, neurogenin-2, Sox2, and P-cadherin are expressed in RPCs.

\section{Conclusion}

There are many strategies for the replacement of retinal cells in degenerative eye diseases:

producing photoreceptor cells from fetal tissue, 2- generating photoreceptors from stem cells (Retinal Progenitor Cells (RPC), Embryonic Stem Cells (ESC), induced pluripotent stem cells (iPS), or mesenchymal stem cells (MSC), and 3- generating photoreceptors by therapeutic cloning (Hogan et al., 1971; MacLaren \& Pearson, 2007; Messina et al., 2011; Stern \& Temple, 2011). The embryonic stem cells are the most common type for differentiation and clinical trial in retinal disease, but they have limitations such as ethical, immune rejection, and tumorigenesis.

Although the iPS cells lack many problems like ESCs, but short, rapid telomerase activity and aging in differentiated cells are the main problems.

Extraocular mesenchyme factors act as an inducer of differentiation, as the optic vesicle stage. Also, adult RPE cells secrete factors that affect adjacent cells. The studies showed that the Activin-like factor released from EOM causes the expression of Mitf and Otx2 for RPE specification. We hypothesized here that this factor might act on neural stem cells and stimulate them for the production of Mitf. Besides, FGFs released from EOM cause the expression of ERK in the neural retina that stimulates expression of Sox 2 and Vsx2, for the retinal specification. Therefore, FGFs from EOM could affect neural stem cells and stimulate them to produce Sox2, Vsx2. These factors also may affect adult RPE cells and cause transdifferentiation into retinal cells. The combination effect of Sox2, Vsx2, and transdifferentiation of RPE cells could stimulate the neural stem cells for differentiation into retinal cells. We suggested that the expression of Pax6 in neural stem cells is the beginning of the differentiation of the neural retina, like to optic vesicle stage in development. Besides, factors buried from EOM provide the essential signals for neural retina morphogenesis and RPE differentiation. By this method, neural stem cells, under the coculture condition with EOM and RPE may get potential for differentiation into retinal progenitor cells 


\section{Ethical Considerations}

\section{Compliance with ethical guidelines}

All study procedures followed the ethical standards of the responsible committee on human experimentation (Semnan University of Medical Sciences, Semnan, Iran) and were in accordance with the Helsinki Declaration of 1975, as revised in 2013.

\section{Funding}

The project was funded by Farabi Research Center at Farabi Hospital, Tehran, Iran. We are also grateful for the support of the Nervous System Stem Cell Research Center of School of Medicine, Semnan University of Medical Sciences, Semnan, Iran.

\section{Conflict of interest}

The author declared no conflict of interest.

\section{Acknowledgments}

We thank Dr. Elham Khademloo for the chemistry advice and Elahe Khademloo for designing the schematic of figures.

\section{References}

Kadkhodaeian, H. A., Tiraihi, T., Ahmadieh, H., Ardakani, H. Z., Daftarian, N., \& Taheri, T. (2018). Survival and migration of adipose-derived stem cells transplanted in the injured retina. Experimental and Clinical Transplantation, 16(2), 204-11. https:/ /d1wqtxts1xzle7.cloudfront.net/58412830/2016

Adler, R., \& Canto-Soler, M. V. (2007). Molecular mechanisms of optic vesicle development: Complexities, ambiguities and controversies. Developmental Biology, 305(1), 1-13. [DOI:10.1016/0012-1606(81)90342-0] [PMID] [PMCID]

Araki, M., \& Okada, T. (1977). Differentiation of lens and pigment cells in cultures of neural retinal cells of early chick embryos. Developmental Biology, 60(1), 278-86. [DOI:10.1016/00121606(77)90124-5]

Aruta, C., Giordano, F., De Marzo, A., Comitato, A., Raposo, G., \& Nandrot, E. F., et al. (2011). In vitro differentiation of retinal pigment epithelium from adult retinal stem cells. Pigment Cell \& Melanoma Research, 24(1), 233-40. [DOI:10.1111/j.1755148X.2010.00793.x] [PMID]

Bae, K. S., Park, J. B., Kim, H. S., Kim, D. S., Park, D. J., \& Kang, S. J. (2011). Neuron-like differentiation of bone marrow-derived mesenchymal stem cells. Yonsei Medical Journal, 52(3), 401-12. [DOI:10.3349/ymj.2011.52.3.401] [PMID] [PMCID]
Barry, F. P., \& Murphy, J. M. (2004). Mesenchymal stem cells: Clinical applications and biological characterization. The International Journal of Biochemistry \& Cell Biology, 36(4), 568-84. [DOI:10.1016/j.biocel.2003.11.001] [PMID]

Bharti, K., Gasper, M., Ou, J., Brucato, M., Clore-Gronenborn, K., \& Pickel, J., et al. (2012). A regulatory loop involving PAX6, MITF, and WNT signaling controls retinal pigment epithelium development. PLoS Genetics, 8(7), e1002757. [DOI:10.1371/ journal.pgen.1002757] [PMID] [PMCID]

Bharti, K., Miller, S. S., \& Arnheiter, H. (2011). The new paradigm retinal pigment epithelium cells generated from embryonic or induced pluripotent stem cells. Pigment Cell \& Melanoma Research, 24(1), 21-34. [DOI:10.1111/j.1755-148X.2010.00772.x] [PMID] [PMCID]

Bharti, K., Nguyen, M. T. T., Skuntz, S., Bertuzzi, S., \& Arnheiter, H. (2006). The other pigment cell: specification and development of the pigmented epithelium of the vertebrate eye. Pigment Cell \& Melanoma Research, 19(5), 380-94. [DOI:10.1111/ j.1600-0749.2006.00318.x] [PMID] [PMCID]

Brzezinski, J. A., \& Reh, T. A. (2015). Photoreceptor cell fate specification in vertebrates. Development, 142(19), 3263-73. [DOI:10.1242/dev.127043] [PMID] [PMCID]

Burmeister, M., Novak, J., Liang, M.-Y., Basu, S., Ploder, L., \& Hawes, N. L., et al. (1996). Ocular retardation mouse caused by $\mathrm{Chx} 10$ homeobox null allele: Impaired retinal progenitor proliferation and bipolar cell differentiation. Nature Genetics, 12(4), 376. [DOI:10.1038/ng0496-376] [PMID]

Caplan, A. I. (1991). Mesenchymal stem cells. Journal of Orthopaedic Research, 9(5), 641-50. [DOI:10.1002/jor.1100090504] [PMID]

Carido, M., Zhu, Y., Postel, K., Benkner, B., Cimalla, P., \& Karl, M. O., et al. (2014). Characterization of a mouse model with complete RPE loss and its use for RPE cell transplantation RPE cell transplantation in a mouse model. Investigative Oph thalmology \& Visual Science, 55(8), 5431-44. [DOI:10.1167/ iovs.14-14325] [PMID]

Catacchio, I., Berardi, S., Reale, A., De Luisi, A., Racanelli, V., \& Vacca, A., et al. (2013). Evidence for bone marrow adult stem cell plasticity: Properties, molecular mechanisms, negative aspects, and clinical applications of hematopoietic and mesenchymal stem cells transdifferentiation. Stem Cells International, 2013. [DOI:10.1155/2013/589139] [PMID] [PMCID]

Cho, M. S., Kim, S. J., Ku, S. Y., Park, J. H., Lee, H., \& Yoo, D. H., et al. (2012). Generation of retinal pigment epithelial cells from human embryonic stem cell-derived spherical neural masses. Stem cell research, 9(2), 101-109. [DOI:10.1016/j. scr.2012.05.002] [PMID]

Choi, K. S., Shin, J. S., Lee, J. J., Kim, Y. S., Kim, S. B., \& Kim, C. W. (2005). In vitro trans-differentiation of rat mesenchymal cells into insulin-producing cells by rat pancreatic extract. Biochemical and Biophysical Research Communications, 330(4), 1299305. [DOI:10.1016/j.bbrc.2005.03.111] [PMID]

Clayton, R., Pomerai, D., \& Pritchard, D. (1977). Experimental manipulation of alternative pathways of differentiation in cultures of embryonic chick neural retina. Development, Growth \& Differentiation, 19(4), 319-28. [DOI:10.1111/j.1440169X.1977.00319.x]

Cwinn, M. A., Mazerolle, C., McNeill, B., Ringuette, R., Thurig S., \& Hui, C. C., et al. (2011). Suppressor of fused is required 
to maintain the multipotency of neural progenitor cells in the retina. Journal of Neuroscience, 31(13), 5169-80. [DOI:10.1523/ JNEUROSCI.5495-10.2011] [PMID] [PMCID]

De Iongh, R., \& McAvoy, J. (1993). Spatio-temporal distribution of acidic and basic FGF indicates a role for FGF in rat lens morphogenesis. Developmental Dynamics, 198(3), 190-202. [DOI:10.1002/aja.1001980305] [PMID]

Deng, W., Obrocka, M., Fischer, I., \& Prockop, D. J. (2001). In vitro differentiation of human marrow stromal cells into early progenitors of neural cells by conditions that increase intracellular cyclic AMP. Biochemical and Biophysical Research Communications, 282(1), 148-52. [DOI:10.1006/bbrc.2001.4570] [PMID]

Dong, X., Pulido, J. S., Qu, T., \& Sugaya, K. (2003). Differentiation of human neural stem cells into retinal cells. Neuroreport, 14(1), 143-6. [DOI:10.1097/00001756-200301200-00026] [PMID]

Duan, P., Xu, H., Zeng, Y., Wang, Y., \& Yin, Z. Q. (2013). Human bone marrow stromal cells can differentiate to a retinal pigment epithelial phenotype when co-cultured with pig retinal pigment epithelium using a transwell system. Cellular Physiology and Biochemistry, 31(4-5), 601-13. [DOI:10.1159/000350080] [PMID]

Dutt, K., Douglas, P., \& Cao, Y. (2010). RPE-secreted factors: influence differentiation in human retinal cell line in dose-and density-dependent manner. Journal of Ocular Biology, Diseases, and Informatics, 3(4), 144-60. [DOI:10.1007/s12177-011-9076-4] [PMID] [PMCID]

Egusa, H., Schweizer, F. E., Wang, C. C., Matsuka, Y., \& Nishimura, I. (2005). Neuronal differentiation of bone marrow-derived stromal stem cells involves suppression of discordant phenotypes through gene silencing. Journal of Biological Chemistry, 280(25), 23691-97. [DOI:10.1074/jbc.M413796200] [PMID]

Elner, S. G., Elner, V. M., Kindzelskii, A. L., Horino, K., Davis, H. R., \& Todd III, R. F., et al. (2003). Human RPE cell lysis of extracellular matrix: Functional urokinase Plasminogen Activator Receptor (uPAR), collagenase and elastase. Experimental Eye Research, 76(5), 585-95. [DOI:10.1016/S0014-4835(03)00028-9]

Faigle, R., \& Song, H. (2013). Signaling mechanisms regulating adult neural stem cells and neurogenesis. Biochimica et Biophysica Acta (BBA)-General Subjects, 1830(2), 2435-48. [DOI:10.1016/j. bbagen.2012.09.002] [PMID] [PMCID]

Fuhrmann, S. (2010). Eye morphogenesis and patterning of the optic vesicle. Current Topics in Developmental Biology, 93, 61. [DOI:10.1016/B978-0-12-385044-7.00003-5] [PMID] [PMCID]

Fuhrmann, S., Levine, E. M., \& Reh, T. A. (2000). Extraocular mesenchyme patterns the optic vesicle during early eye development in the embryonic chick. Development, 127(21), 4599-609. https://dev.biologists.org/content/127/21/4599.short

Fujimura, J., Ogawa, R., Mizuno, H., Fukunaga, Y., \& Suzuki, H. (2005). Neural differentiation of adipose-derived stem cells isolated from GFP transgenic mice. Biochemical and biophysical Research Communications, 333(1), 116-121. [DOI:10.1016/j. bbrc.2005.05.096] [PMID]

Fujimura, N., Taketo, M. M., Mori, M., Korinek, V., \& Kozmik, Z (2009). Spatial and temporal regulation of Wnt/ $\beta$ catenin signaling is essential for development of the retinal pigment epithelium. Developmental Biology, 334(1), 31-45. [DOI:10.1016/j. ydbio.2009.07.002] [PMID]
Galy, A., Neron, B., Planque, N., Saule, S., \& Eychene, A. (2002). Activated MAPK/ERK kinase (MEK-1) induces transdifferentiation of pigmented epithelium into neural retina. Developmental Biology, 248(2), 251-64. [DOI:10.1006/dbio.2002.0736] [PMID]

Green, E. S., Stubbs, J. L., \& Levine, E. M. (2003). Genetic rescue of cell number in a mouse model of microphthalmia: interactions between Chx10 and G1-phase cell cycle regulators. Development, 130(3), 539-52. [DOI:10.1242/dev.00275] [PMID]

Guillemot, F., \& Cepko, C. L. (1992). Retinal fate and ganglion cell differentiation are potentiated by acidic FGF in an in vitro assay of early retinal development. Development, 114(3), 743754. https://dev.biologists.org/content/114/3/743.short

Hatzistergos, K. E., Quevedo, H., Oskouei, B. N., Hu, Q., Feigenbaum, G. S., \& Margitich, I. S., et al. (2010). Bone marrow mesenchymal stem cells stimulate cardiac stem cell proliferation and differentiationnovelty and significance. Circulation Research, 107(7), 913-922. [DOI:10.1161/CIRCRESAHA.110.222703] [PMID] [PMCID]

Hennig, A. K., Peng, G.-H., \& Chen, S. (2008). Regulation of photoreceptor gene expression by $\mathrm{Crx}$-associated transcription factor network. Brain Research, 1192, 114-33. [DOI:10.1016/j. brainres.2007.06.036] [PMID] [PMCID]

Hirashima, M., Kobayashi, T., Uchikawa, M., Kondoh, H., \& Araki, M. (2008). Anteroventrally localized activity in the optic vesicle plays a crucial role in the optic development. Developmental Biology, 317(2), 620-31. [DOI:10.1016/j. ydbio.2008.03.010] [PMID]

Hodgkinson, C. A., Moore, K. J., Nakayama, A., Steingrímsson, E., Copeland, N. G., \& Jenkins, N. A., et al. (1993). Mutations at the mouse microphthalmia locus are associated with defects in a gene encoding a novel basic-helix-loop-helix-zipper protein. Cell, 74(2), 395-404. [DOI:10.1016/0092-8674(93)90429-T]

Horsford, D. J., Nguyen, M. T. T., Sellar, G. C., Kothary, R. Arnheiter, H., \& McInnes, R. R. (2005). Chx10 repression of Mitf is required for the maintenance of mammalian neuroretinal identity. Development, 132(1), 177187. [DOI:10.1242/ dev.01571] [PMID]

Huch, M., \& Koo, B. K. (2015). Modeling mouse and human development using organoid cultures. Development, 142(18), 3113-25. [DOI:10.1242/dev.118570] [PMID]

Hyer, J., Mima, T., \& Mikawa, T. (1998). FGF1 patterns the optic vesicle by directing the placement of the neural retina domain. Development, 125(5), 869-877. https://dev.biologists. org/content/125/5/869.short

Itoh, Y., Okada, T., Ide, H., \& Eguchi, G. (1975). The differentiation of pigment cells in cultures of chick embryonic neural retinae. Development, Growth \& Differentiation, 17(1), 39-50. [DOI:10.1111/j.1440-169X.1975.00039.x]

Jiang, J., Lv, Z., Gu, Y., Li, J., Xu, L., \& Xu, W., et al. (2010). Adult rat mesenchymal stem cells differentiate into neuronal-like phenotype and express a variety of neuro-regulatory molecules in vitro. Neuroscience Research, 66(1), 46-52. [DOI:10.1016/j.neures.2009.09.1711] [PMID]

Kagiyama, Y., Gotouda, N., Sakagami, K., Yasuda, K., Mochii, M., \& Araki, M. (2005). Extraocular dorsal signal affects the developmental fate of the optic vesicle and patterns the optic neuroepithelium. Development, Growth \& Differentiation, 47(8), 523-36. [DOI:10.1111/j.1440-169X.2005.00828.x] [PMID] 
Kelly, T. K., Karsten, S. L., Geschwind, D. H., \& Kornblum, H. I. (2009). Cell lineage and regional identity of cultured spinal cord neural stem cells and comparison to brain-derived neural stem cells. PloS One, 4(1), e4213. [DOI:10.1371/journal. pone.0004213] [PMID] [PMCID]

Korte, G. E., Reppucci, V., \& Henkind, P. (1984). RPE destruction causes choriocapillary atrophy. Investigative Ophthalmology $\mathcal{E}$ Visual Science, 25(10), 1135-1145. https:/ / pdfs.semanticscholar.org/425e/3fa613876df0258b2705f26b89092c5c76ea.pdf

Krabbe, C., Zimmer, J., \& Meyer, M. (2005). Neural transdifferentiation of mesenchymal stem cells-a critical review. Apmis, 113(11-12), 831-44. [DOI:10.1111/j.1600-0463.2005. apm_3061.x] [PMID]

Kuhn, H. G., \& Eisch, A. J. Editors, (2014). Neural stem cells in development, adulthood and disease. Springer. [DOI:10.1007/9781-4939-1908-6]

Lamba, D. A., Karl, M. O., Ware, C. B., \& Reh, T. A. (2006). Efficient generation of retinal progenitor cells from human embryonic stem cells. Proceedings of the National Academy of Sciences, 103(34), 12769-74. [DOI:10.1073/pnas.0601990103] [PMID] [PMCID]

Levkovitch-Verbin, H., Sadan, O., Vander, S., Rosner, M., Barhum, Y., \& Melamed, E., et al. (2010). Intravitreal injections of neurotrophic factors secreting mesenchymal stem cells are neuroprotective in rat eyes following optic nerve transection. Investigative Ophthalmology \& Visual Science, 51(12), 6394-400. [DOI:10.1167/iovs.09-4310] [PMID]

Li, Y., Atmaca-Sonmez, P., Schanie, C. L., Ildstad, S. T., Kaplan, H. J., \& Enzmann, V. (2007). Endogenous bone marrowderived cells express retinal pigment epithelium cell markers and migrate to focal areas of RPE damage. Investigative Ophthalmology \& Visual Science, 48(9), 4321-7. [DOI:10.1167/ iovs.06-1015] [PMID]

Machalińska, A., Baumert, B., Kuprjanowicz, L., Wiszniewska, B., Karczewicz, D., \& Machaliński, B. (2009). Potential application of adult stem cells in retinal repair-challenge for regenerative medicine. Current Eye Research, 34(9), 748-60. [DOI:10.1080/02713680903050592] [PMID]

MacLaren, R., \& Pearson, R. (2007). Stem cell therapy and the retina. Eye, 21(10), 1352. [DOI:10.1038/sj.eye.6702842] [PMID]

Mead, B., Berry, M., Logan, A., Scott, R. A., Leadbeater, W., \& Scheven, B. A. (2015). Stem cell treatment of degenerative eye disease. Stem Cell Research, 14(3), 243-57. [DOI:10.1016/j. scr.2015.02.003] [PMID] [PMCID]

Messina, A., Casarosa, S., \& Murenu, E. (2011). Stem Cells and the Retina-Challenges for Regenerative Medicine. Embryonic Stem Cells-Recent Advances in Pluripotent Stem CellBased Regenerative Medicine. InTech. Open access Peer. [DOI:10.5772/14780]

Mochii, M., Mazaki, Y., Mizuno, N., Hayashi, H., \& Eguchi, G. (1998). Role of Mitf in differentiation and transdifferentiation of chicken pigmented epithelial cell. Developmental Biology, 193(1), 47-62. [DOI:10.1006/dbio.1997.8800] [PMID]

Montzka, K., Lassonczyk, N., Tschöke, B., Neuss, S., Führmann, T., \& Franzen, R., et al. (2009). Neural differentiation potential of human bone marrow-derived mesenchymal stromal cells: misleading marker gene expression. BMC Neuroscience, 10(1), 16. [DOI:10.1186/1471-2202-10-16] [PMID] [PMCID]
Moviglia, G. A., Blasetti, N., Zarate, J. O., \& Pelayes, D. E. (2012) In vitro differentiation of adult adipose mesenchymal stem cells into retinal progenitor cells. Ophthalmic Research, 48(Suppl. 1), 1-5. [DOI:10.1159/000339839] [PMID]

Müller, F., Rohrer, H., \& Vogel-Höpker, A. (2007). Bone morphogenetic proteins specify the retinal pigment epithelium in the chick embryo. Development, 134(19), 3483-93. [DOI:10.1242/ dev.02884] [PMID]

Nakamura, Y., de Paiva Alves, E., Veenstra, G. J. C., \& Hoppler, S. (2016). Tissue-and stage-specific Wnt target gene expression is controlled subsequent to $\beta$-catenin recruitment to cis-regulatory modules. Development, 143(11), 1914-25. [DOI:10.1242/dev.131664] [PMID] [PMCID]

Nguyen, M., \& Arnheiter, H. (2000). Signaling and transcriptional regulation in early mammalian eye development: a link between FGF and MITF. Development, 127(16), 3581-91. https:/ / dev.biologists.org/content/127/16/3581.short

Opas, M., Davies, J. R., Zhou, Y., \& Dziak, E. (2004). Formation of retinal pigment epithelium in vitro by transdifferentiation of neural retina cells. International Journal of Developmental Biology, 45(4), 633-42. http://www.ijdb.ehu.es/web/paper. php?doi=11460999

Pandit, T., Jidigam, V. K., Patthey, C., \& Gunhaga, L. (2015) Neural retina identity is specified by lens-derived BMP signals. Development, 142(10), 1850-9. [DOI:10.1242/dev.123653] [PMID] [PMCID]

Park, C. M., \& Hollenberg, M. J. (1989). Basic fibroblast growth factor induces retinal regeneration in vivo. Developmental biology, 134(1), 201-5. [DOI:10.1016/0012-1606(89)90089-4]

Peng, G. H., Ahmad, O., Ahmad, F., Liu, J., \& Chen, S. (2005) The photoreceptor-specific nuclear receptor Nr2e3 interacts with $\mathrm{Crx}$ and exerts opposing effects on the transcription of rod versus cone genes. Human Molecular Genetics, 14(6), 74764. [DOI:10.1093/hmg/ddi070] [PMID]

Pittack, C., Grunwald, G. B., \& Reh, T. A. (1997). Fibroblast growth factors are necessary for neural retina but not pigmented epithelium differentiation in chick embryos. Development, 124(4), 805-16. https://dev.biologists.org/content/124/4/805.short

Ramrattan, R. S., van der Schaft, T. L., Mooy, C. M., De Bruijn, W., Mulder, P., \& De Jong, P. (1994). Morphometric analysis of Bruch's membrane, the choriocapillaris, and the choroid in aging. Investigative Ophthalmology \& Visual Science, 35(6), 2857-2864. https://iovs.arvojournals.org/article. aspx?articleid $=2179814$

Redi, C. (2011). Adult stem cells-Biology and methods of analysis. European Journal of Histochemistry, 55(4), 14. [DOI:10.4081/ ejh.2011.br14]

Rowan, S., Chen, C.-M. A., Young, T. L., Fisher, D. E., \& Cepko, C. L. (2004). Transdifferentiation of the retina into pigmented cells in ocular retardation mice defines a new function of the homeodomain gene Chx10. Development, 131(20), 5139-52. [DOI:10.1242/dev.01300] [PMID]

Scheven, C. (2015). Existence of localizable solutions to nonlinear parabolic problems with irregular obstacles. Manuscripta Mathematica, 146(1-2), 7-63. [DOI:10.1007/s00229-014-0684-8]

Sernagor, E., Eglen, S., Harris, B., \& Wong, R. (2012). Retinal development. Cambridge University Press. 
Sevlever, G., Miriuka, S., \& Pitossi, F. (2015). Differentiation of mesenchymal stem cells into retinal progenitor cells. Ophthalmic Research, 53(1), 28-9. [DOI:10.1159/000365218] [PMID]

Singh, M. S., \& MacLaren, R. E. (2011). Stem cells as a therapeutic tool for the blind: biology and future prospects. Proceedings of the Royal Society B: Biological Sciences, 278(1721), 3009-16. [DOI:10.1098/rspb.2011.1028] [PMID] [PMCID]

Sinn, R., \& Wittbrodt, J. (2013). An eye on eye development. Mechanisms of Development, 130(6-8), 347-58. [DOI:10.1016/j. mod.2013.05.001] [PMID]

Stern, J. H., \& Temple, S. (2011). Stem cells for retinal replacement therapy. Neurotherapeutics, 8(4), 736-43. [DOI:10.1007/ s13311-011-0077-6] [PMID] [PMCID]

Swaroop, A., Kim, D., \& Forrest, D. (2010). Transcriptional regulation of photoreceptor development and homeostasis in the mammalian retina. Nature Reviews Neuroscience, 11(8), 563-76. [DOI:10.1038/nrn2880] [PMID]

Tang, K., Xie, X., Park, J. I., Jamrich, M., Tsai, S., \& Tsai, M. J. (2010). COUP-TFs regulate eye development by controlling factors essential for optic vesicle morphogenesis. Development, 137(5), 725-34. [DOI:10.1242/dev.040568] [PMID] [PMCID]

Temple, S. (2001). The development of neural stem cells. Nature, 414(6859), 112. [DOI:10.1038/35102174] [PMID]

Turner, D. A., Hayward, P. C., Baillie-Johnson, P., Rué, P., Broome, R., \& Faunes, F., et al. (2014). Wnt/ $\beta$ catenin and FGF signalling direct the specification and maintenance of a neuromesodermal axial progenitor in ensembles of mouse embryonic stem cells. Development, 141(22), 4243-53. [DOI:10.1242/ dev.112979] [PMID] [PMCID]

Vogel-Höpker, A., Momose, T., Rohrer, H., Yasuda, K., Ishihara, L., \& Rapaport, D. H. (2000). Multiple functions of Fibroblast Growth Factor-8 (FGF-8) in chick eye development. Mechanisms of Development, 94(1-2), 25-36. [DOI:10.1016/S09254773(00)00320-8]

Wang, S. Z. (2017). Retinal development: Methods and protocols. Springer. https://link.springer.com/book/10.1007/978-161779-848-1

Weiner, L. P. (2008). Neural stem cells: methods and protocols (Vol. 438). Springer Science \& Business Media. [DOI:10.1007/9781-59745-133-8]

Westenskow, P. D., McKean, J. B., Kubo, F., Nakagawa, S., \& Fuhrmann, S. (2010). Ectopic Mitf in the embryonic chick retina by co-transfection of $\beta$-catenin and Otx2. Investigative Ophthalmology \& Visual Science, 51(10), 5328-35. [DOI:10.1167/ iovs.09-5015] [PMID] [PMCID]

Wong, I. Y.-H., Poon, M.-W., Pang, R. T.-W., Lian, Q., \& Wong, D. (2011). Promises of stem cell therapy for retinal degenerative diseases. Graefe's Archive for Clinical and Experimental Ophthalmology, 249(10), 1439. [DOI:10.1007/s00417-011-1764-z] [PMID] [PMCID]

Wong, K. A., Trembley, M., Wahab, S. A., \& Viczian, A. S. (2015) Efficient retina formation requires suppression of both Activin and BMP signaling pathways in pluripotent cells. Biology Open, 4(4), 573-83. [DOI:10.1242/bio.20149977] [PMID] [PMCID]

Woodbury, D., Reynolds, K., \& Black, I. B. (2002). Adult bone marrow stromal stem cells express germline, ectodermal endodermal, and mesodermal genes prior to neurogenesis. Journal of Neuroscience Research, 69(6), 908-17. [DOI:10.1002/ jnr.10365] [PMID]

Xiang, M. (2013). Intrinsic control of mammalian retinogenesis. Cellular and Molecular Life Sciences, 70(14), 25192532. [DOI:10.1007/s00018-012-1183-2] [PMID] [PMCID]

Xu, W., \& Xu, G. X. (2011). Mesenchymal stem cells for retinal diseases. International Journal of Ophthalmology, 4(4), 413-21. [PMCID] [PMID]

Xu, Y., Liu, Z., Liu, L., Zhao, C., Xiong, F., \& Zhou, C., et al (2008). Neurospheres from rat adipose-derived stem cells could be induced into functional Schwann cell-like cells in vitro. BMC Neuroscience, 9(1), 21. [DOI:10.1186/1471-2202-921] [PMID] [PMCID]

Yang, X. J. (2004). Roles of cell-extrinsic growth factors in vertebrate eye pattern formation and retinogenesis. In Seminars in Cell \& Developmental Biology, 15(1), 91-103.[DOI:10.1016/j. semcdb.2003.09.004] [PMID] [PMCID]

Young, R. W., \& Bok, D. (1970). Autoradiographic studies on the metabolism of the retinal pigment epithelium. Investigative Ophthalmology \& Visual Science, 9(7), 524-536. https://iovs. arvojournals.org $/$ article .aspx? articleid $=2203446$

Yuan, H. P., Ge, J., Duan, Y. H., Wang, Y. M., Wang, L. N., \& Yang, B. B. (2003). Induced differentiation of neural stem cells from subependymal zone into retinal cells in vitro. [Zhonghua yan ke za zhi] Chinese journal of ophthalmology, 39(6), 357-60. [PMID]

Zaghloul, N. A., Yan, B., \& Moody, S. A. (2005). Step-wise specification of retinal stem cells during normal embryogenesis. Biology of the Cell, 97(5), 321-37. [DOI:10.1042/BC20040521] [PMID]

Zarbin, M. A. (2004). Current concepts in the pathogenesis of age-related macular degeneration. Archives of Ophthalmology, 122(4), 598-614. [DOI:10.1001/archopht.122.4.598] [PMID]

Zhou, S., Flamier, A., Abdouh, M., Tétreault, N., Barabino, A., \& Wadhwa, S., et al. (2015). Differentiation of human embryonic stem cells into cone photoreceptors through simultaneous inhibition of BMP, TGF $\beta$ and Wnt signaling. Development, 142(19), 3294-306. [DOI:10.1242/dev.125385] [PMID]

Zigova, T., Sanberg, P. R., \& Sanchez-Ramos, J. R. (2002). Neural stem cells: methods and protocols (Vol. 198). Springer Science \& Business Media. [DOI:10.1385/1592591868] [PMID] 
This Page Intentionally Left Blank 